\title{
SPECTROSCOPIC FAMILIES OF DIFFUSE INTERSTELLAR BANDS
}

\author{
B. Wszolek ${ }^{1}$, E. Nagel ${ }^{2}$ \\ ${ }^{1}$ Pedagogical University, \\ 13/15 Armii Krajowej Str., Częstochowa, Poland \\ ${ }^{2}$ Jagiellonian University Astronomical Observatory, \\ 171 Orlast Cracow, Poland \\ (Received July 22, 2002)
}

\begin{abstract}
In this work we are trying to find spectroscopic 'relatives' for two prominent diffuse interstellar bands (DIBs) 5780 and 5797. We have used two methods; averaging equivalent widths (EWs) and visual investigation of the figures with arranged spectrograms. On the basis of our analysis we suggest some candidates as members of two spectroscopic families with 5780 and 5797 bands as principal structures.
\end{abstract}

Key words: diffuse interstellar bands, interstellar matter, spectroscopic families.

PACS number(s): 98.38.Am

\section{INTRODUCTION}

Diffuse interstellar bands (e.g. Herbig [1]), absorption structures of interstellar origin, still await their explanation. The identification of the carrier(s) of DIBs became one of the most difficult tasks for spectroscopists.

One tries, in general, to solve the mystery of the car$\operatorname{rier}(\mathrm{s})$ of DIBs on the field of interdisciplinary spectroscopic collaboration between molecular physicists, molecular chemists and astronomers. One expects that some progress in this field will be possible when all the known DIBs are divided into families in such a way that only one carrier is responsible for all bands belonging to the given family. Such families of bands we call 'spectroscopic' ones, to distinguish them from 'characterological' families isolated by the authors cited below.

First findings of the DIB families were done in the middle eighties. Chlewicki et. al. [2] divided strong DIBs into two families; the criteria of segregation were the degree of correlation between reddening $\mathrm{E}(\mathrm{B}-\mathrm{V})$ of the target star and intensity of the DIB.

Krełowski and Walker [3] selected three families among the known DIBs. Structures belonging to each family were defined as groups of bands whose strengths in different lines of sight are more closely correlated with one another than with other DIBs, and which obey common dependence on reddening.

The trials to divide DIBs into families cited above were very preliminary as far as spectroscopic families are considered. In order to try to identify a carrier of a given family one needs well defined series of spectral bands (with strong bands as well as weak ones) originating from a single substance.

The number of DIBs has grown dramatically in recent years, primarily due to better quality of observational material. More and more weak DIBs (WDIBs) seem to appear every time when a given spectral region is analysed carefully. The aim of this report is to explore further the properties of DIBs in the context of isolating spectroscopic families of these structures.

\section{OBSERVATIONAL MATERIAL}

All the spectra analysed for the purpose of this work were taken from the archives of professor Jacek Krełowski (Astronomical Centre, Nicolaus Copernicus University, Torun, Poland). We used the spectra taken with CFHT (described by Snow and Seab [4]) and those acquired at the McDonald Observatory with echelle spectrograph fed with the $2.1 \mathrm{~m}$. telescope (Krelowski and Sneden [5]). Relatively high quality of these observational data allowed us to measure the EWs for many strong and weak DIBs.

\section{DATA ANALYSIS}

The aim of our analysis was to find spectroscopic relatives to strong 5780 and 5797 bands which, as was shown by Krełowski and Westerlund [6], belong to different spectroscopic families (names of DIBs we give here as wavelengths corresponding to the centres of the individual bands, given in angstroms). We have selected spectra covering spectral range from 5750 to $5860 \AA$ for 74 stars and we have measured EWs for 11 WDIBs 5760, 5763, 5766, 5769, 5773, 5776, 5793, 5795, 5809, 5819 and 5829 , as well as for two relatively strong DIBs - 5780 and 5797. Extremely low EWs of WDIBs (in most cases less than $0.01 \AA$ ) make their measurements very difficult. Avoiding of large errors of the measured parameters was impossible. In such a case one looks for an adequate method to find any possible correlation between individual WDIBs and chosen strong DIBs.

Statistical correlation not always gives us entirely satisfying results because bands which do not belong to the same spectroscopic family are usually very well mutually correlated in statistical sense. We had to by-pass in some way the problem of such 'noise' correlation. We have used two simple but promising methods described below. 


\section{A. The averaging EWs method}

To check mutual dependence between WDIBs and 5780 and 5797 bands we have started from the following procedure. We extracted a sample with
EW(5797) restricted to a very narrow range of values. From such a sample we separated two subsamples: the first one with relatively low, and the second one with relatively high values of $\mathrm{EW}(5780)$.

\begin{tabular}{|c|c|c|c|c|c|c|c|c|c|c|c|c|c|}
\hline HD & 5780 & 5797 & 5760 & 5763 & 5766 & 5769 & 5773 & 5776 & 5793 & 5795 & 5809 & 5819 & 5829 \\
\hline 24912 & 194 & 50 & 2 & 4 & 10 & 3 & 5 & 8 & 2 & 4 & - & - & 6 \\
\hline 54662 & 195 & 49 & 3 & - & 9 & 5 & - & 6 & 7 & 4 & 3 & 7 & 2 \\
\hline 147933 & 200 & 57 & 7 & 8 & 9 & 9 & 8 & 7 & 5 & 5 & 6 & 3 & 7 \\
\hline 164402 & 170 & 55 & 3 & - & 7 & 2 & 12 & 10 & - & - & 1 & 2 & 2 \\
\hline 193443 & 302 & 56 & - & - & 13 & 10 & 15 & 10 & 4 & 7 & - & 4 & - \\
\hline $\begin{array}{c}\text { mean } \\
\text { value in } \\
\text { the group }\end{array}$ & 212.2 & 53.4 & 3.75 & 6 & 9.6 & 5.8 & 10 & 8.2 & 4.5 & 5 & 3.33 & 4 & 4.25 \\
\hline 148184 & 96 & 51 & 1 & 3 & 8 & 8 & - & - & 3 & 2 & - & 2 & 5 \\
\hline 199579 & 111 & 55 & 2 & 2 & 9 & 6 & 6 & 4 & 5 & 4 & 2 & - & - \\
\hline 216200 & 114 & 47 & - & 5 & - & - & 15 & - & - & - & 3 & - & 9 \\
\hline 218376 & 108 & 46 & 3 & 4 & 4 & 2 & 4 & 2 & 2 & 2 & 2 & 3 & 1 \\
\hline 223128 & 112 & 52 & 4 & 5 & 6 & 1 & - & - & 6 & 3 & 4 & 12 & 5 \\
\hline $\begin{array}{c}\text { mean } \\
\text { value in } \\
\text { the group }\end{array}$ & 108.2 & 50.2 & 2.5 & 3.8 & 6.75 & 4.25 & 8.67 & 3 & 4 & 2.75 & 2.75 & 5.67 & 5 \\
\hline $\begin{array}{c}\text { very } \\
\text { probable } \\
\text { corelation } \\
\text { with } 5780\end{array}$ & & & & & & & & + & & + & & & \\
\hline
\end{tabular}

Table 1. Two subsamples of stars chosen in such a way that average EW(5797) is almost constant in both subsamples contrary to EW(5780) which in first subsamples is almost twice as large as in the second one. The names of bands are listed in the first row, whereas names of target stars used are given in the first column of the table. In both subsamples for each band the mean value of measured EWs was counted. The sign "-" stands for the lack of the data and "+" indicates interesting examples of correlation (see text).

\begin{tabular}{|c|c|c|c|c|c|c|c|c|c|c|c|c|c|}
\hline HD & 5780 & 5797 & 5760 & 5763 & 5766 & 5769 & 5773 & 5776 & 5793 & 5795 & 5809 & 5819 & 5829 \\
\hline 42087 & 255 & 100 & 5 & 5 & - & 7 & - & 7 & 7 & 5 & 3 & - & 6 \\
\hline 206267 & 238 & 105 & 3 & 5 & 15 & 8 & 8 & 6 & 6 & 4 & 3 & 4 & 4 \\
\hline 207198 & 252 & 152 & 7 & 9 & 22 & 11 & 12 & 7 & 13 & 6 & - & 7 & 12 \\
\hline 208501 & 255 & 113 & 4 & 6 & 9 & 5 & - & - & 7 & 6 & 8 & 11 & 8 \\
\hline $\begin{array}{c}\text { mean } \\
\text { value in } \\
\text { the group }\end{array}$ & $\mathbf{2 5 0}$ & $\mathbf{1 1 7 . 5}$ & $\mathbf{4 . 7 5}$ & $\mathbf{6 . 2 5}$ & $\mathbf{1 5 . 3 3}$ & $\mathbf{7 . 7 5}$ & $\mathbf{1 0}$ & $\mathbf{6 . 6 7}$ & $\mathbf{8 . 2 5}$ & $\mathbf{5 . 2 5}$ & $\mathbf{4 . 6 7}$ & $\mathbf{7 . 3 3}$ & $\mathbf{7 . 5}$ \\
\hline 13267 & 275 & 69 & 6 & 3 & 4 & - & 7 & 8 & 6 & 8 & 4 & 9 & 3 \\
\hline 14134 & 277 & 77 & - & - & 16 & 7 & 12 & 15 & - & - & 5 & 5 & 6 \\
\hline 14489 & 274 & 77 & 3 & 5 & 6 & 6 & 8 & 8 & 6 & - & - & - & 3 \\
\hline 147165 & 237 & 32 & - & 2 & 10 & - & - & 5 & 2 & 6 & 6 & 2 & 1 \\
\hline 152408 & 278 & 43 & - & - & - & - & 9 & 4 & 5 & 5 & 3 & 1 & 2 \\
\hline 166937 & 277 & 71 & 3 & 5 & 14 & - & - & - & 5 & 9 & 9 & 12 & 7 \\
\hline 167263 & 280 & 72 & - & - & 12 & 10 & 11 & 6 & - & - & 2 & 2 & 3 \\
\hline $\begin{array}{c}\text { mean } \\
\text { value in } \\
\text { the group }\end{array}$ & $\mathbf{2 7 1 . 1 4}$ & $\mathbf{6 3}$ & $\mathbf{4}$ & $\mathbf{3 . 7 5}$ & $\mathbf{1 0 . 3 3}$ & $\mathbf{7 . 6 7}$ & $\mathbf{9 . 4}$ & $\mathbf{7 . 6 7}$ & $\mathbf{4 . 8}$ & $\mathbf{7}$ & $\mathbf{4 . 8 3}$ & $\mathbf{5 . 1 7}$ & $\mathbf{3 . 2 9}$ \\
\hline $\begin{array}{c}\text { very } \\
\text { probable } \\
\begin{array}{c}\text { corelation } \\
\text { with 5797 }\end{array}\end{array}$ & & & & & & & & & & & & & \\
\hline
\end{tabular}

Table 2. The same as in Table 1 but here the mean EW(5780) is rather stable whereas EW(5797) drops almost twice when going from the first subsample to the second one. 
In these sub-samples we calculated mean values of EW(5780), EW(5797) and EWs for WDIBs. Both subsamples, as well as results of averaging, are exposed in Table 1. WDIBs correlated with 5780 should follow changes in EW(5780), contrary to those which are not correlated.

In a similar way we have extracted a sample of stars with almost constant EW(5780) and separated subsamples with opposite values of EW(5797), see Table 2. Such a simple procedure allowed us to divide considered WDIBs into three groups; (i) well correlated with 5780 (5776 and 5795), (ii) well correlated with 5797 (5793, 5819 and 5829) and (iii) rather not correlated neither with 5780 nor $5797(5769,5773$ and 5809). Three other cases $(5760,5763$ and 5766) are rather complicated because they seem to be correlated with 5797 as well as with 5780 . The main selecting criterion was here a gradient of the average value for WDIBs. If this gradient, for considered WDIB, is evidently similar to the gradient which is typical for the head band (in our case this gradient is very close to 0.5 ), we decided to include this WDIB into the family.

\section{B. Investigating the figures with arranged spectrograms}

Another way to divide WDIBs into three, above mentioned, groups consists in visual inspection of spectrograms. If we compose sequences of spectrograms in such a way that EW(5780), for example, is constant and EW(5797) gradually increases (Figure 1), we are able, after visual inspection of the picture, indicate WDIBs which follow, and those ones which do not follow, the behaviour of 5797 .

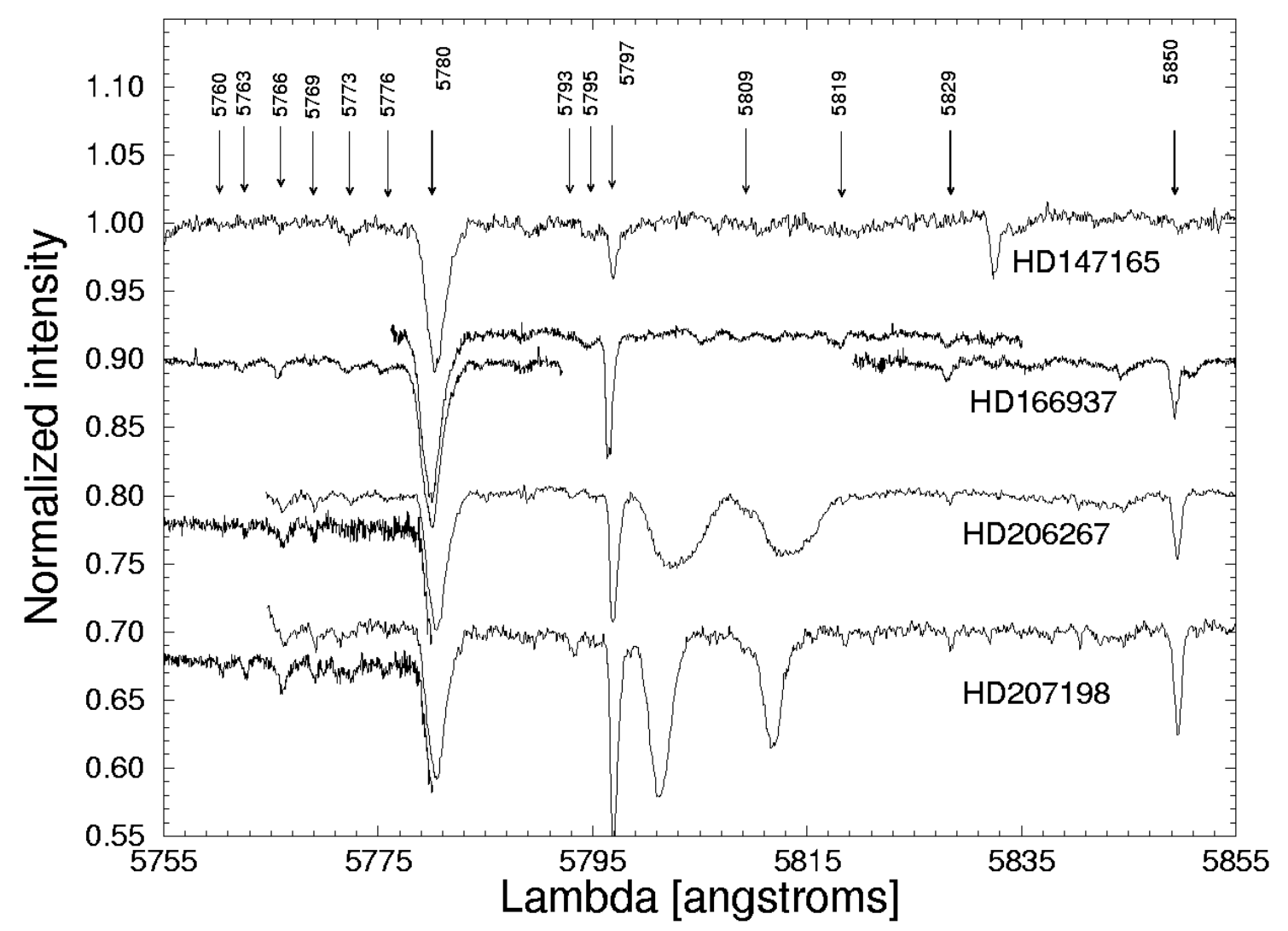

Fig. 1. CFHT (the longest pieces) and McDonald's (shorter, individual orders of echelle spectrograph) spectrograms arranged in such a way that strength of 5797 band gradually increases whereas intensity of 5780 band remains constant.

Figure 2 shows the case of nearly constant EW(5797) and changing EW(5780). Inspection of Figures 1 and 2 does not contradict but confirm results achieved with the earlier described averaging procedure. 


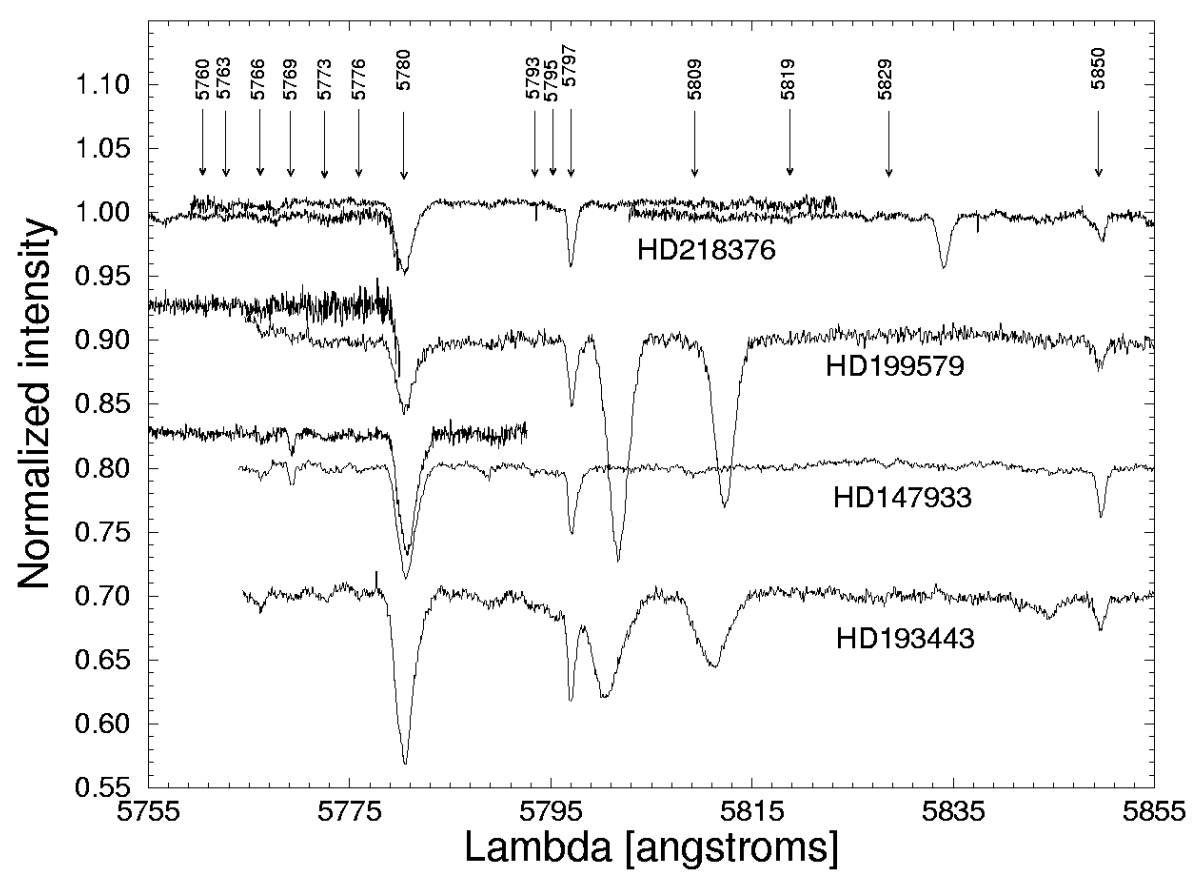

Fig. 2. Similar to Figure 1, but here the roles of 5780 and 5797 bands are exchanged. Intensity of the first band increases whereas the strength of the second one remains constant.

\section{CONCLUSIONS}

Methods described in subchapters III.A and III.B are appropriate to extract spectroscopic families of DIBs. Using them we performed very preliminary separation of two presumable (probably not complete yet) spectroscopic families: (i) 5780, 5776 and 5795, and (ii) 5793 , $5797,5819,5829$ and 5850 .

One cannot, however, exclude such a possibility that we made wrong indications. In the case of almost constant ratios between column densities of various DIB carriers in interstellar clouds we have a chance of getting results which are quite similar to those when we have to deal with few spectral lines of the same carrier. Further investigations based on better data samples and involving other spectral ranges are necessary to isolate true spectroscopic families of bands.

\section{ACKNOWLEDGEMENT}

We would like to thank professor Jacek Krełowski for giving us the open ran to his data archives as well as to his specialised software.
[1] G. H. Herbig, Ann. Rev. Astron. Astrophys. 33, 19 (1995).

[2] G. Chlewicki, van der G. P. Zwet, van L. J. Ijzendoorn, J. M. Greenberg, Astrophys. J. 305, 455 (1986).

[3] J. Krełowski, G. A. H. Walker, Astrophys. J. 312, 860 (1987)
[4] T. P. Snow, C. G. Seab, Astrophys. J. 382, 189 (1991).

[5] J. Krełowski, C. Sneden, Publ. Astron. Soc. Pac. 105, 1141 (1993).

[6] J. Krełowski, B. E. Westerlund, Astron. Astrophys. 190, 339 (1988).

\title{
СПЕКТРОСКОПІЧНА РОДИНА ДИФУЗНИХ МІЖЗОРЯНИХ СМУГ
}

\author{
Б. Вшолек ${ }^{1}$, Е. Нагель ${ }^{2}$ \\ ${ }^{1}$ Педагогічний університет, Ченстохова, Польща \\ ${ }^{2}$ Ягеллонсъкий університет, Астрономічна обсерваторія, Краків, Польща \\ e-mail:bogdan@oa.uj.edu.pl,bogdan@wsp.czest.pl
}

Зроблено спробу знайти спектроскопічні відповідники для двох відомих дифузних міжзоряних смуг (DIBs) 5780 i 5797. Використано два методи усереднення еквівалентних ширин (EWs) і візуальне дослідження фігур з упорядкованими спектрограмами. На основі аналізу запропоновано декілька кандидатів у члени двох спектральних сімейств зі смугами 5780 і 5797 як основні структури. 